\title{
Пространственно-временная структура избыточного увлажнения на юго-востоке Западной Сибири в XX и начале XXI века
}

\author{
О.С. Литвинова ${ }^{\varpi}$ \\ Новосибирский государственный педагогический университет, Российская Федераџия \\ (630126, г. Новосибирск, ул. Вилюйская, 28)
}

\begin{abstract}
Аннотация: Цель: исследовать пространственно-временную структуру избыточного увлажнения на юго-востоке Западной Сибири.

Meтоды и материаль. На основе расчета и анализа индекса атмосферного увлажнения Si по 9 метеостанциям юго-востока Западной Сибири за период с 1950 по 2017 годы, изучена пространственно-временная структура избыточного увлажнения: $-2,0<\mathrm{Si}<-1,1$ - слабого переувлажнения; $-3,0<\mathrm{Si}<-2,1$ - переувлажнения средней степени, $\mathrm{Si}<-3,1$ - сильного переувлажнения. В работе проведен регрессионный анализ между избыточным увлажнением и предшествующими условиями теплои влагообеспеченности текущего и предыдущего года. Анализ линейных трендов позволил определить общую тенденцию изменения индекса $\mathrm{Si}$ за май-сентябрь.

Результаты и обсуждение. Нормальное увлажнение наблюдается в 50 \% случаев. Формирование «влажных периодов» различной степени интенсивности возможно в любом месяце и может продолжаться с мая по сентябрь. В большинстве случаев в исследуемом регионе отмечалось слабое переувлажнение $(-2,0<\mathrm{Si}<-1,1)$. Избыточное увлажнение одновременно бывает в среднем примерно на двух станциях. Повторяемость влажных периодов в XXI веке уменьшилось в 2-3 раза.

Заключение. Наиболее тесная связь формирования избыточного увлажнения получена для августа при дефиците осадков ( $<80 \%$ нормы), в сентябре на западе региона и в ноябре - на юго-востоке. За период 1950-2017 годов в августе в южных и юго-восточных районах выявлена тенденция уменьшения повторяемости избыточного увлажнения различной степени интенсивности, что свидетельствует о повышение засушливости территории в теплый период.
\end{abstract}

Ключевые слова: Западная Сибирь, крупномасштабный индекс атмосферного увлажнения, вегетационный период, избыточно увлажненные условия.

Для цитирования: Литвинова О.С. Пространственно-временная структура избыточного увлажнения на юго-востоке Западной Сибири в XX и начале XXI века // Вестник Воронежского государственного университета. Серия: География. Геоэкология, 2020, № 3, с. 24-31. DOI: https://doi.org/10.17308/geo.2020.3/3020

\section{ВВЕДЕНИЕ}

Растущая повторяемость аномальных природных явлений из-за глобальных изменений климата (на территории Российской Федерации в 2018 г. зарегистрировано на 133 явление больше, чем в 2017 г.), в том числе атмосферных засух и избыточно влажных периодов вызывает интерес у ученых многих стран мира. Хотя усилия исследователей направлены на выявление причин их формирования и разработку способов прогноза, однако многие климатические аспекты еще не изучены в должной мере.
Как отмечается в оценочном докладе об изменениях климата и их последствиях на территории Российской Федерации в последние пять десятилетий отмечается повышение температуры воздуха в зимнем сезоне и увеличение продолжительности вегетационного периода, что в свою очередь оказывает влияние на развитие сельского хозяйства [1]. Для смягчения последствий климатических воздействий на региональном уровне необходимо проведение комплексных исследований.

Регион охватывает территорию Омской, Новосибирской, Томской областей и Алтайского края,

() Литвинова О.С., 2020

\ Литвинова Ольга Сергеевна, e-mail: olg.litwino2011@ yandex.ru Контент доступен под лицензией Creative Commons Attribution 4.0 License. 


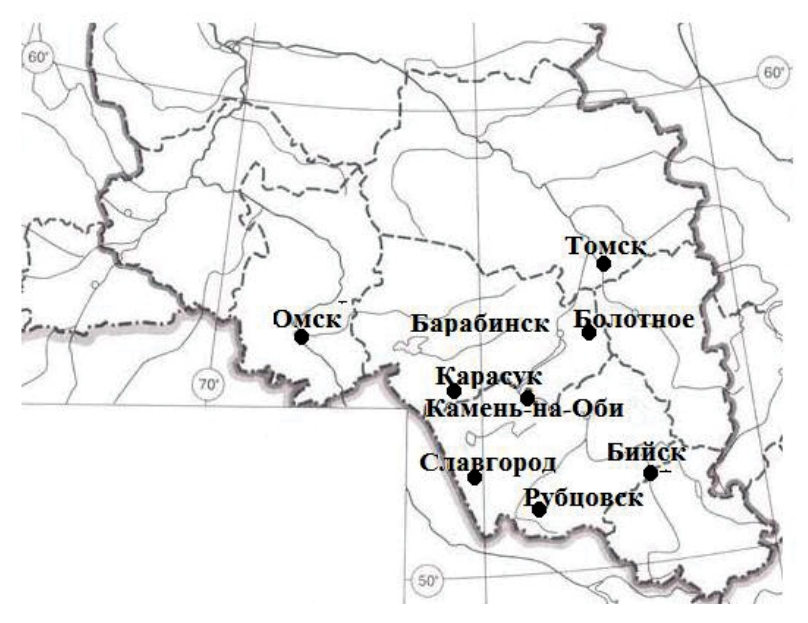

Рuc. 1. Метеорологические станции юго-востока Западной Сибири

[Fig. 1. Meteorological stations in the south-east of Western Siberia]

для него характерен континентальный климат умеренных широт. Открытость территории на севере и юге способствует свободному проникновению холодных арктических и прогретых континентальных умеренных воздушных масс.

Большой урон зерновым культурам наносят и дефицит, и избыточное выпадение атмосферных осадков продолжительностью более двух месяцев. Влажные периоды с температурой воздуха ниже нормы и выпадением осадков $\geq 120 \%$ (особенно в 3 декаде августа) способствует развитию болезней колоса, и снижению урожайности [2]. Переувлажненное состояние почв в весенний период (особенно в микрозападинах) оказывает влияние на смещение дат начала полевых работ [3]. В частности, в мае 2018 г. в Сибирском Федеральном округе (особенно в южных районах) отмечалась отрицательная аномалия температуры воздуха (на 8-12 $\mathrm{C}$ ниже нормы) из-за доминирования северного и северо-западного переноса воздуха (с районов бассейна Северного Ледовитого океана). Частое прохождение циклонов, связанных с ними атмосферных фронтов через южные районы Сибири сопровождалось выпадением обильных осадков, их количество превысило норму в 1,5-3,5 раза. Холодная с частыми осадками погода апреля-мая сдерживала просыхание верхних слоев почвы, выход техники в поля был затруднен, а зачастую невозможен.

Настоящая работа является продолжением исследования [4], в котором изучены особенности формирования атмосферных засух различной интенсивности.
Цель настоящего исследования - определить пространственно-временную структуру избыточного увлажнения на юго-востоке Западной Сибири.

\section{МЕТОДЫ И МАТЕРИАЛЫ}

Для статистических оценок использованы данные вегетационного периода с 1950 по 2017 год 9 метеорологических станций (рис. 1) [5, 6].

В качестве крупномасштабного индекса использовался показатель Д. А. Педя [7], который характеризует различную интенсивность засушливых и избыточно увлажненных условий: $\mathrm{Si}>3,1$ - сильная засуха, 2,1< $\mathrm{Si} \leq 3,0$ - засуха средней степени; $1,1<\mathrm{Si} \leq 2,0$ - засуха слабой степени; $-1,0<\mathrm{Si} \leq 1,0$ - нормальное увлажнение; $-2,0<\mathrm{Si}<-1,1$ - слабое переувлажнение; $-3,0<\mathrm{Si}<-2,1$ - переувлажнение средней степени, $\mathrm{Si}<-3,1-$ сильное переувлажнение.

На основе анализа линейных трендов определялась общая тенденция изменения индекса $\mathrm{Si}$, регрессионного анализа - теснота связи избыточно увлажненных условий различной интенсивности от предшествующих условий тепло- и влагообеспеченности осенне-зимнего и весеннего сезонов.

\section{РЕЗУЛЬТАТЫ И ОБСУЖДЕНИЕ}

На рассматриваемой территории выявлены тенденции повышения температуры воздуха в теплом периоде - в апреле $\left(0,5^{\circ} \mathrm{C} / 10\right.$ лет) и мае (0,3ㄷ10 лет).

Крупномасштабный индекс Si учитывает разницу аномалий температуры воздуха и атмосферных осадков, и их среднеквадратические отклонения [7]. Следует отметить, что значения индекса $\mathrm{Si}$ обусловлены территориальными закономерностями барико-циркуляционного режима в исследуемом регионе, и оказывают влияние на урожайность зерновых культур.

На юго-востоке Западной Сибири атмосферные осадки изменяются не только зонально (уменьшаются с севера на юг от 592 мм (Томск) до 353 мм (Славгород)), но и азонально (возрастая в восточном направлении от 441 мм (Омск) до 614 мм (Бийск)). В теплом периоде выпадает до $75 \%$ годовой суммы осадков [8].

Повторяемость избыточно увлажненных условий различной интенсивности определена за период с 1950 до 2017 года. Нормальное увлажнение наблюдается в $50 \%$ случаев. Избыточно увлажненные условия всех типов формируются на территории юго-востока Западной Сибири с мая по сентябрь. 
Значимые коэффициенты множественной корреляции между индексами атмосферного увлажнения $(-2,0<\mathrm{Si}<-1,1 ; \mathrm{Si}<-2,1)$ и предшествующими условиями тепло- и влагообеспеченности

[Table 1. Significant coefficients of multiple correlation between the indices of atmospheric humidification $(-2,0<\mathrm{Si}<-1,1 ; \mathrm{Si}<-2,1)$ and the previous conditions of heat and moisture supply]

\begin{tabular}{|c|c|c|c|c|}
\hline $\begin{array}{l}\text { Метеостанция/ } \\
\text { Weatherstation }\end{array}$ & $\mathrm{n}$ & $\begin{array}{l}\text { Вид зависимости / } \\
\text { Dependence type }\end{array}$ & $\mathrm{R}$ & $\begin{array}{c}\mathrm{t}_{\mathrm{r}} \text {-критерий } \\
\text { Стьюдента / } \\
\mathrm{t}_{\mathrm{r}} \text {-Student's } \mathrm{t} \text { test }\end{array}$ \\
\hline Томск & 17 & $S i_{V I I I}=0,09 t_{I I}-0,67$ & 0,46 & 2,02 \\
\hline Болотное & 18 & $S i_{V I I}=0,16 t_{I V}+0,02 X_{I V}-3,11$ & 0,74 & 3,$55 ; 2,59$ \\
\hline \multirow[t]{2}{*}{ Омск } & 19 & $\begin{array}{c}S i_{V I}=-0,09 t_{T}-3,94 \\
S i_{V I}=0,01 X_{I X}-0,24 t_{X}-1,94\end{array}$ & $\begin{array}{l}0,57 \\
0,59\end{array}$ & $\begin{array}{c}-2,86 \\
2,13 ;-2,34\end{array}$ \\
\hline & 18 & $\begin{array}{c}S i_{V I I I}=-0,09 t_{I}+0,20 t_{I I}-0,04 X_{I I}+0,29 \\
S i_{V I I I}=-0,04 X_{I X}-0,02 X_{X I}-0,23\end{array}$ & $\begin{array}{l}0,76 \\
0,70 \\
\end{array}$ & $\begin{array}{c}-2,6 ; 4,1 ;-2,0 \\
-2,93 ;-2,60 \\
\end{array}$ \\
\hline \multirow[t]{4}{*}{ Барабинск } & 20 & $S i_{V I}=0,12 t_{I I I}-0,10 t_{I V}-0,37$ & 0,59 & 2,$80 ;-2,17$ \\
\hline & 18 & $\begin{array}{c}S i_{V I I}=0,03 X_{I I}+0,08 t_{I I I}-0,21 t_{I V}-0,15 X_{I V}+2,36 \\
S i_{V I I}=0,03 X_{I I}-0,24 t_{V I}-0,02 X_{V I}+2,22\end{array}$ & $\begin{array}{l}0,88 \\
0,80\end{array}$ & $\begin{array}{c}2,9 ; 3,0 ;-3,4 ;-4,6 \\
2,3 ;-3,2 ;-4,72\end{array}$ \\
\hline & 16 & $\begin{array}{c}S i_{V I I I}=-0,06 X_{I I}-0,06 X_{I V}+0,18 \\
S i_{V I I I}=0,04 X_{I}-0,13 X_{I I}+0,06 X_{I I I}-0,05 X_{I V}-0,74\end{array}$ & $\begin{array}{l}0,74 \\
0,90\end{array}$ & $\begin{array}{c}-2,21 ;-3,46 \\
3,18 ;-4,65 ; 3,20 \\
-4,45\end{array}$ \\
\hline & 17 & $S i_{I X}=0,32 t_{I V}-0,02 X_{V I I}-1,88$ & 0,71 & 3,$51 ;-2,66$ \\
\hline \multirow[t]{2}{*}{ Карасук } & 18 & $S i_{V}=-0,10 t_{I}+0,08 X_{I}-0,08 X_{I I I}-4,14$ & 0,67 & $-2,3 ; 2,32 ;-2,51$ \\
\hline & 16 & $\begin{array}{c}S i_{V I I I}=0,18 t_{I I}-0,18 t_{I I I}-0,08 X_{I}+0,34 \\
S i_{V I I I}=-0,02 X_{I X}-0,05 X_{X I}-0,09 t_{X I I^{-}}-1,92\end{array}$ & $\begin{array}{l}0,75 \\
0,73\end{array}$ & $\begin{array}{l}3,18 ;-2,62 ; 2,71 \\
-2,1 ;-3,1 ;-2,31\end{array}$ \\
\hline \multirow[t]{4}{*}{$\begin{array}{l}\text { Камень-на- } \\
\text { Оби }\end{array}$} & 18 & $\begin{array}{c}S i_{V I}=0,06 t_{I I}+0,02 X_{V}-1,91 \\
S i_{V I}=0,02 X_{V}-2,99\end{array}$ & $\begin{array}{l}0,82 \\
0,74\end{array}$ & $\begin{array}{c}2,42 ; 4,86 \\
4,50\end{array}$ \\
\hline & 17 & $S i_{V I I}=-0,26 t_{I V}-0,02 X_{V I}-0,16$ & 0,88 & $-5,64 ;-5,62$ \\
\hline & 15 & $S i_{V I I I}=0,28 t_{V I}+0,02 X_{V I}+0,02 X_{V I I}-9,09$ & 0,79 & 2,$14 ; 2,30 ; 2,18$ \\
\hline & 18 & $S i_{I X}=0,32 t_{V I}-7,98$ & 0,59 & 2,95 \\
\hline \multirow[t]{3}{*}{ Бийск } & 17 & $S i_{V I}=-0,09 X_{X I}-0,27 t_{V^{-}}-0,04 X_{I V}+3,45$ & 0,82 & $-2,1 ;-2,77 ;-5,10$ \\
\hline & 19 & $S i_{V I I I}=-0,14 t_{I X}+0,01 X_{X}+0,02 X_{X I}+1,21$ & 0,87 & $-2,33 ; 3,08 ; 6,48$ \\
\hline & 17 & $S i_{I X}=-0,21 t_{I}+0,21 t_{I I}-2,69$ & 0,69 & $-3,58 ; 2,78$ \\
\hline \multirow[t]{3}{*}{ Рубцовск } & 19 & $S i_{V}=0,14 t_{X I}-1,36$ & 0,72 & 4,32 \\
\hline & 17 & $S i_{V I I}=0,15 t_{I I I}-0,22 t_{I V}-0,08$ & 0,64 & 2,$62 ;-2,93$ \\
\hline & 19 & $\begin{array}{c}S i_{V I I I}=0,04 X_{I}+0,02 X_{I V^{-}}-3,29 \\
S i_{V I I I}=0,11 t_{I I I} 0,25 t_{I V}+0,03 X_{V I^{-}}-1,17\end{array}$ & $\begin{array}{l}0,67 \\
0,74\end{array}$ & $\begin{array}{c}2,57 ; 2,55 \\
2,72 ;-3,65 ; 3,57\end{array}$ \\
\hline \multirow[t]{3}{*}{ Славгород } & 18 & $S i_{V}=0,16 t_{I X}-0,27 t_{X}-3,55$ & 0,66 & 2,$12 ;-2,56$ \\
\hline & 18 & $S i_{V I}=-0,42 t_{X}+0,02 X_{X}-1,83$ & 0,70 & $-3,26 ; 2,46$ \\
\hline & 13 & $S i_{V I I I}=0,33 t_{I I I}-2,79 X_{I}+0,03 X_{I V}+1,36$ & 0,90 & 5,$72 ;-2,79 ; 3,54$ \\
\hline
\end{tabular}

Примечание: $n$ - число случаев, $X$ - атмосферные осадки (мм), $t$ - средняя температура воздуха$\left({ }^{\circ} \mathrm{C}\right)$, подстрочные знаки у $X$ и $t$ -

Note: $n$ - number of cases, $X$ - atmospheric precipitation $(\mathrm{mm}), t$-average air temperature $\left({ }^{\circ} \mathrm{C}\right)$, subscripts for $X$ and $t-{ }_{\text {II, IV ... }}-$ month of the year, $R-$ multiple correlation coefficient.

За рассматриваемый период выявлена наибольшая повторяемость слабого переувлажнения: на севере региона (Томск, Болотное) в мае-июле, на западе (Омск) - в июне-августе, на юге (Рубцовск, Славгород) - июнь, сентябрь, на юго-востоке (Бийск) - в мае, и в центральных районах (Барабинск) - в июне.
Переувлажнение средней степени характерно в мае для метеостанций Камень-на-Оби, Славгород, Рубцовск, в июне - Омск, Камень-на-Оби, в августе - Томск, Бийск, и в сентябре - Болотное, Барабинск, Карасук, Камень-на-Оби. Повторяемость сильного переувлажнения за рассматриваемый период не превышает $6 \%$ случаев, в северных районах в мае, в южных - в июне. 
Повторяемость положительных ( $\geq 120 \%)$ и отрицательных $(<80 \%)$ аномалий осадков в осенне-зимний и весенний сезоны за 1950-1917 годы

[Table 2. Repeatability of positive $(\geq 120 \%)$ and negative $(\leq 80 \%)$ precipitation anomalies in the autumn-winter and spring seasons for 1950-1917]

\begin{tabular}{|l|c|c|c|c|c|c|c|c|c|c|}
\hline \multirow{2}{*}{$\begin{array}{c}\text { Метеостанция / } \\
\text { Weatherstation }\end{array}$} & \multicolumn{2}{|c|}{$\mathrm{IX}$} & \multicolumn{2}{c|}{ XI } & \multicolumn{2}{c|}{$\mathrm{I}$} & \multicolumn{2}{|c|}{ II } & \multicolumn{2}{c|}{ IV } \\
\cline { 2 - 12 } & $\mathrm{n} / 20$ & $\mathrm{n} /$ & $\mathrm{n} /$ & $\mathrm{n} /$ & $\mathrm{n} /$ & $\mathrm{n} /$ & $\mathrm{n} /$ & $\mathrm{n} /$ & $\mathrm{n} /$ & $\mathrm{n} /$ \\
& $\geq 120$ & $\leq 80$ & $\geq 120$ & $\leq 80$ & $\geq 120$ & $\leq 80$ & $\geq 120$ & $\leq 80$ \\
\hline Томск & $8 / 47$ & $4 / 24$ & $7 / 41$ & $4 / 24$ & $7 / 41$ & $7 / 41$ & $5 / 29$ & $7 / 41$ & $3 / 18$ & $7 / 41$ \\
\hline Болотное & $4 / 27$ & $7 / 47$ & $4 / 27$ & $6 / 40$ & $3 / 20$ & $6 / 40$ & $6 / 40$ & $5 / 33$ & $2 / 15$ & $8 / 53$ \\
\hline Омск & $3 / 18$ & $11 / 61$ & $6 / 33$ & $7 / 39$ & $8 / 44$ & $6 / 33$ & $6 / 33$ & $8 / 44$ & $7 / 39$ & $8 / 44$ \\
\hline Барабинск & $3 / 19$ & $10 / 63$ & $6 / 38$ & $5 / 31$ & $5 / 31$ & $8 / 50$ & $4 / 25$ & $6 / 38$ & $6 / 38$ & $8 / 50$ \\
\hline Карасук & $6 / 38$ & $6 / 38$ & $5 / 31$ & $7 / 44$ & $5 / 31$ & $9 / 56$ & $2 / 13$ & $9 / 56$ & $7 / 44$ & $7 / 44$ \\
\hline Камень-на-Оби & $3 / 20$ & $7 / 47$ & $5 / 33$ & $5 / 40$ & $5 / 33$ & $7 / 47$ & $6 / 40$ & $7 / 47$ & $9 / 60$ & $5 / 33$ \\
\hline Бийск & $4 / 22$ & $6 / 33$ & $7 / 39$ & $11 / 61$ & $5 / 28$ & $9 / 50$ & $6 / 33$ & $6 / 33$ & $8 / 44$ & $7 / 39$ \\
\hline Рубцовск & $4 / 23$ & $6 / 35$ & $4 / 23$ & $6 / 35$ & $4 / 23$ & $6 / 35$ & $5 / 29$ & $7 / 41$ & $3 / 18$ & $10 / 59$ \\
\hline Славгород & $4 / 31$ & $8 / 61$ & $4 / 31$ & $5 / 38$ & $4 / 31$ & $5 / 38$ & $4 / 31$ & $5 / 38$ & $4 / 31$ & $6 / 46$ \\
\hline
\end{tabular}

Избыточное увлажнение одновременно бывает в среднем примерно на двух станциях. Наибольший охват избыточным увлажнением $(75 \%$ и более площади) характерен для 1960 и 1972 года - в течение трех-пяти месяцев. В 1954, 1958 годах избыточное увлажнение различной степени интенсивности отмечалось в течение трех месяцев на метеостанциях Карасук, Славгород, Рубцовск и Бийск; в 1992 году с июня по сентябрь - в Славгороде.

В 1960 году самым влажным был июль в Омске, Болотное, Барабинске, Карасуке, Славгороде (количество атмосферных осадков выпало больше нормы в 1,5-3 раза). В 1972 году на севере, западе и юго-западе исследуемой территории самым влажным был июнь, на востоке и юго-востоке июль. В 17-21\% случаев влажные условия и избыточное увлажнение были продолжительностью два месяца (чаще всего в Карасуке, Барабинске, Бийске).

Анализ повторяемости числа избыточного увлажнения средней и сильной степени по десятилетиям показал, что самыми влажными были периоды 1951-1960 годы (Бийск, Славгород), 19611970 годы (Омск, Томск), 1951-1960 и 19711980 годы (Болотное, Барабинск, Карасук, Каменьна-Оби, Рубцовск). Повторяемость влажных периодов в XXI веке уменьшилось в 2-3 раза (в большинстве случаев продолжительностью один месяц). В конце десятилетия 1991-2000 годов и в начале 2001-2010 годов отмечались в основном обширные и длительные засухи [4].

Установлено, что определенный вклад в формирование избыточного увлажнения вносят пред- шествующие условия тепло- и влагообеспеченности текущего и предыдущего года (таблицы 1, 2).

Значимые коэффициенты корреляции между индексами атмосферного увлажнения $(-2,0<\mathrm{Si}<-1$; $\mathrm{Si}<-2,1)$ и предшествующими условиями теплои влагообеспеченности выявлены лишь в отдельные месяцы, тем не менее, их вклад может быть существенным.

Тесные связи избыточного увлажнения с предшествующими условиями тепло и влагообеспеченностью текущего и предыдущего года получены для августа для всех пунктов (за исключением Болотное). Температура воздуха в большинстве случаев на всей рассматриваемой территории отмечалась ниже нормы в феврале и марте.

Коэффициенты множественной корреляции между индексами атмосферного увлажнения августа и предшествующими условиями тепло- и влагообеспеченности составили $0,46-0,90, t$-критерий Стьюдента $-2,02 \ldots 5,72$. При уровне значимости 0,05 значение коэффициента корреляции равно 0,23 [10].

Наибольший вклад в формирование избыточного увлажнения различной степени интенсивности в августе вносит дефицит атмосферных осадков (выпадение осадков менее $80 \%$ от нормы) в сентябре на западе (Омск - $61 \%$ случаев), в ноябpe - на юго-востоке (Бийск - $63 \%$ случаев), в январе - в центральных районах (Барабинск, Карасук $-50-56 \%$ случаев), в феврале - на западе (Омск - $44 \%$ случаев) и в апреле - в центральных районах (Барабинск - $50 \%$ случаев) и на юге (Славгород, Рубцовск - 46-59\% случаев). 


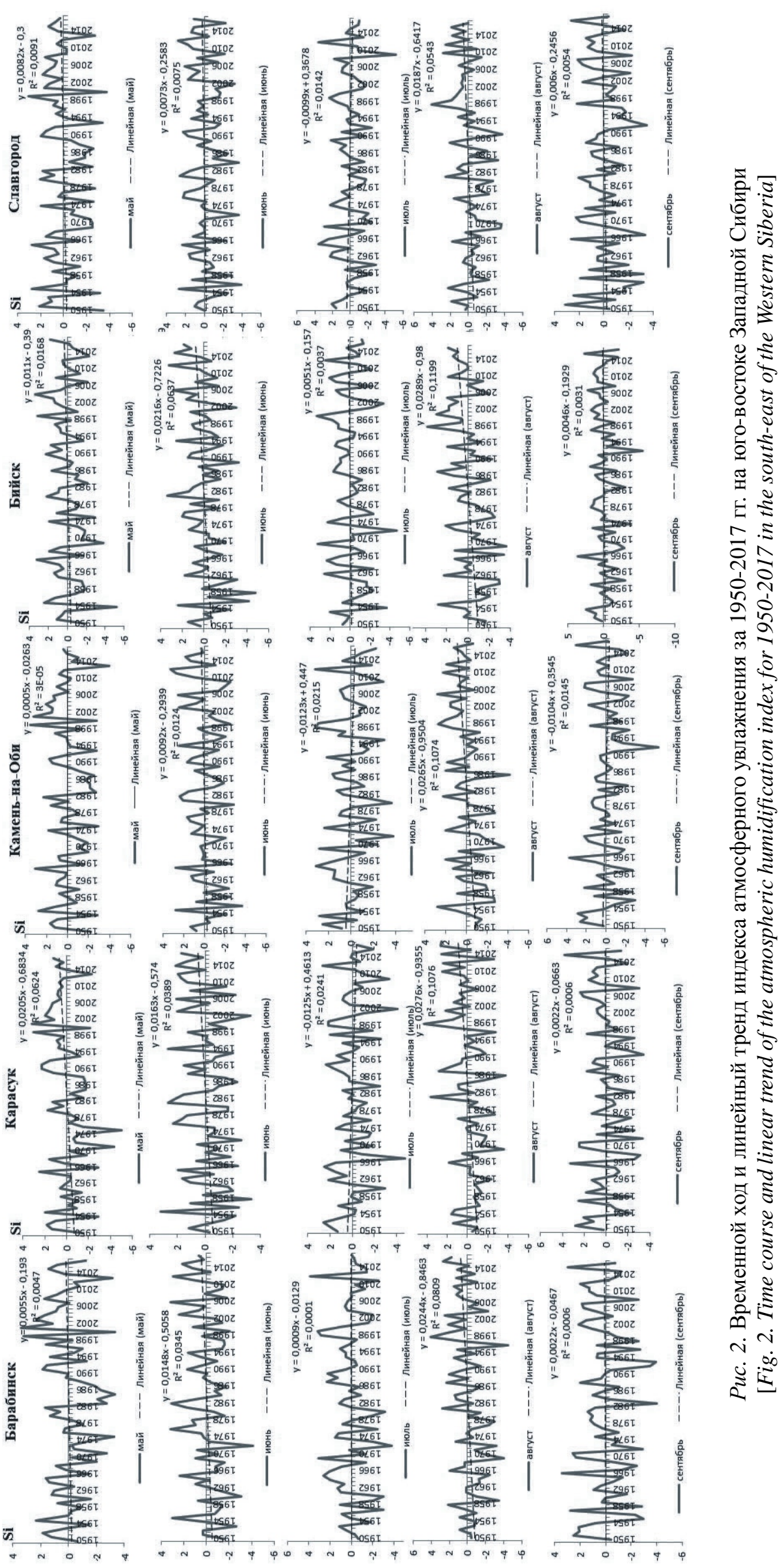


При движении с севера на юг исследуемого региона (за исключением, Рубцовска) в августе увеличивается повторяемость засушливых условий (рис. 2). За исследуемый период отмечается увеличение индекса $\mathrm{Si}$ в центральных и южных районах - Карасук (май, август), Камень-на-Оби (август), Бийск (июнь, август) и Барабинск, Славгород (август). В июле на всей исследуемой территории выявлена статистически не значимая тенденция уменьшения индекса Si.

\section{ЗАКЛЮЧЕНИЕ}

Согласно проведенному исследованию пространственно-временной структуры избыточного увлажнения на юго-востоке Западной Сибири за 1950-2017 годы, можно сделать следующие выводы.

1. Избыточное увлажнение различной интенсивности может формироваться в любом месяце, и продолжаться с мая по сентябрь.

2. Тесные связи избыточного увлажнения с предшествующими условиями тепло и влагообеспеченностью текущего и предыдущего года получены для августа для всей рассматриваемой территории (за исключением Болотное).

3. За период 1950-2017 годы в августе в южных и юго-восточных районах выявлена тенденция уменьшения повторяемости избыточного увлажнения различной степени интенсивности, что свидетельствует о повышение засушливости территории в теплый период.

4. Близкие климатические циклы температуры и осадков наблюдаются над соседним на юге граничащем с Западной Сибирью Казахстаном [10].

\section{СПИСОК ЛИТЕРАТУРЫ}

1. Второй оценочный доклад Росгидромета об изменениях климата и их последствиях на территории Российской Федерациии. М., Росгидромет, 2014. 60 с.
2. Доклад об особенностях климата на территории Российской Федераџии за 2018 год. М., Росгидромет, $2019.79 \mathrm{c}$.

3. Капустянчик С. Ю., Добротворская Н. И. Особенности гидротермических условий почв в лесостепи Новосибирского Приобья // Вестник Алтайского государственного аграрного университета, 2015, № 6 (128), c. 54-58.

4. Литвинова О.С., Гуляева Н.В. Анализ временных рядов осадков Обь-Иртышского междуречья в XX - начале XXI вв. // Динамика окружающей среды и глобальные изменения климата. Ханты-Мансийск. Кафедра ЮНЕСКО Югорского государственного университета, 2010, № 1, с. 38-45.

5. Литвинова О.С., Гуляева Н. В. Макроциркуляционные условия атмосферных засух на юге Урала и Западной Сибири в XX начале XXI вв. // Электронный научно-методический журнал Омского ГАУ, 2017, № $1(8)$, c. 47.

6. Литвинова О. С., Гуляева Н. В. Структура фаз летнего сезона на юго-востоке Западной Сибири // Географический вестник, 2016, № 4 (39), с. 57-69.

7. Педь Д. А. О показателе засухи и избыточного увлажнения // Труды ГМЦ СССР, 1975, вып. 156, с. 19-39.

8. Шаманин В.П., Моргунов А.И., Петуховский С. Л., Трущенко А.Ю., Потоцкая И.В., Краснова Ю. С., Каракоз И. И., Пушкарев Д. В. Потепление климата и урожайность яровой пшеницы в условиях южной лесостепи Западной Сибири // Современные проблемы науки и образования, 2014, № 1, с. 383-393.

9. Шторм Р. Теория вероятностей. Математическая статистика. Статистический контроль качества. М., Мир, 1970. 344 с.

10. Чередниченко А. В., Чередниченко А. В., Чередниченко В.С. Современные климатические циклы во временных рядах температуры и осадков над Казахстаном // Вестник Воронежского государственного университета. Серия: География. Геоэкология, 2017, № 4, c. 15-34.

Конфликт интересов: Автор декларирует отсутствие явных и потенциальных конфликтов интересов, связанных с публикацией настоящей статьи.

Поступила в редакиию 29.11.2019 Принята к публикачии: 26.07.2020 


\title{
Spatial and Temporal Structure of Over Humidificationin the South-East of the Western Siberiain the XX-th and Beginning of the XXI Centuries
}

\author{
O.S. Litvinova $\bowtie$ \\ Novosibirsk State Pedagogical University, Russian Federation \\ (28, Viluyskaya St., Novosibirsk, 630126)
}

\begin{abstract}
The purpose of the study is to study the spatial-temporal structure of excessive moisture in the South-East of the Western Siberia.

Methods and materials. This paper is based on calculation and analysis of the atmospheric humidity index (Si) for 9 weather stations in the South-East of the Western Siberia for the period from 1950 to 2017, the spatial and temporal structure of over humidification was studied: $-2,0<\mathrm{Si}<-1,1$ - weak waterlogging; $-3,0<\mathrm{Si}<-2,1-$ medium waterlogging, $\mathrm{Si}<-3,1-$ strong waterlogging. In this paper, a regression analysis is performed between over humidification and previous conditions of heat and moisture supply in the current and previous years. Analysis of linear trends allowed us to determine the General trend of the Si index for May to September.

Results and discussion. Normal hydration is observed in $50 \%$ of cases. The forming of "wet periods" of different intensity is possible in any month, and can lasts from May to September. A slight over humidification $(-2,0<\mathrm{Si}<-1,1)$ had been noted in the South East of Western Siberia. At the same time excess moisture is on average approximately two stations. The frequency of wet periods in the XXI century decreased by 2-3 times.

Conclusion. The author analyzes a difference between over humidification and the heat and moisture during the current and previous years. The closest points between forming of over humidification were obtained: in August according to a precipitation deficit ( $\leq 80 \%$ out of the norm); in September - in the West of the region, and in November - in the South East. During the period of 1950-2017, in August in the southern and South-Eastern regions, a tendency to reduce the frequency of excessive humidification of various degrees of intensity was revealed, which indicates an increase in the aridity of the territory during the warm period.
\end{abstract}

Key words: Western Siberia, large-scale index of atmospheric humidity, vegetation period, excessively humid conditions.

For citation: Litvinova O.S. Spatial and temporal structure of over humidification in the SouthEast of the Western Siberia in the XX-th and beginning of the XXI centuries. Vestnik Voronezskogo gosudarstvennogo universiteta. Geografia geoekologia, 2020, No. 3, pp. 24-31. (In Russ.) DOI: https://doi.org/10.17308/geo.2020.3/3020

\section{REFERENCES}

1. Vtoroy otsenochnyy doklad Rosgidrometa ob izmeneniyakh klimata I ikh posledstviyakh na territorii Rossiyskoy Federatsii [The second assessment report by Roshydromet on climate change and its consequences on the territory of the Russian Federation]. Moscow, Roshydromet Publ., 2014. 60 p. (In Russ.)

2. Doklad ob osobennostyakh klimata na territorii Rossiyskoy Federatsiiza 2018 god [The report on climate features in the Russian Federation for 2018]. Moscow, Roshydromet Publ., 2019. 79 p. (In Russ.)

3. Kapustyanchik S. Yu., Dobrotvorskaya N. I. Osobennosti gidrotermicheskikh usloviy pochv v lesostepi Novosibirskogo Priob'ya [Features of hydrothermal conditions

(C) Litvinova O.S., 2020

Olga S. Litvinova, e-mail: olg.litwino2011@yandex.ru of soils in the forest-steppe of the Novosibirsk Ob Region]. Bulletin of the Altai State Agrarian University, 2015, no. 6 (128), pp. 54-58. (In Russ.)

4. Litvinova O. S., Gulyaeva N. V. Analiz vremennykh ryadov osadkov Ob'-Irtyshskogo mezhdurech'ya v XXnachale XXI vv [Analysis of the time series of precipitation of the Ob-Irtysh interfluve in the 20-th and early 21-st centuries]. Environmental dynamics and global climate change. Khanty-Mansiysk. UNESCO Chair of Ugra State University, 2010, no. 1, pp. 38-45. (In Russ.)

5. Litvinova O. S., Gulyaeva N. V. Makrotsirkulyatsionnyye usloviya atmosfernykh zasukh na yuge Urala i Zapadnoy Sibiri v XX nachale XXI vv. [Macro-circulation conditions of atmospheric droughts in the South of the Urals and Western Siberia in the XX and early XXI centuries].

The content is available under Creative Commons Attribution 4.0 License. 
Electronic Scientific and Methodological Journal of the Omsk State Agrarian University, 2017, no. 1 (8), pp. 47. (In Russ.)

6. Litvinova O.S., Gulyaeva N. V. Struktura faz letnego sezona na yugo-vostoke Zapadnoy Sibiri [The phase structure of the summer season in the Southeast of Western Siberia]. Geographical Bulletin, 2016, no. 4 (39), pp. 5769. (In Russ.)

7. Ped D. A. O pokazatele zasukhi i izbytochnogo uvlazhneniya [On drought and excess moisture indicator]. Transactions of the USSR State Center for Hydromechanics, 1975, issue 156, pp. 19-39. (In Russ.)

8. Shamanin V.P., Morgunov A. I., Petukhovskiy S. L., Trushchenko A. Yu., Pototskaya I. V., Krasnova Yu. S., Karakoz I. I., Pushkarev D. V. Potepleniye klimata i urozhaynost' yarovoy pshenitsy v usloviyakh yuzhnoy lesostepi Zapadnoy Sibiri [Climate warming and spring wheat produc-

Литвинова Ольга Сергеевна

кандидат географических наук, доцент кафедры географии, регионоведения и туризма, Новосибирский государственный педагогический университет, г. Новосибирск, Российская Федерация, ORCID: https://orcid.org/ 0000-0003-3225-5465, e-mail: olg.litwino2011@ yandex.ru tivity in the conditions of the southern forest-steppe of Western Siberia]. Modern problems of science and education, 2014, no. 1, pp. 383-393. (In Russ.)

9. Storm R. Teoriya veroyatnostey. Matematicheskaya statistika. Statisticheskiy kontrol' kachestva [Probability Theory. Mathematical statistics. Statistical quality control]. Moscow, Mir Publ., 1970. 344 p. (In Russ.)

10. Cherednichenko A. V., Cherednichenko A. V., Cherednichenko V.S. Sovremennye klimaticheskie tsikly vo vremennykh ryadakh temperatury i osadkov nad Kazakhstanom [Modern climate cycles within time-series of temperature and downfalls over Kazakhstan]. Vestnik Voronezskogo gosudarstvennogo universiteta. Geografia geoekologia, 2017, no. 4, pp. 15-34. (In Russ.)

Conflict of interests: The author declares no information of obvious and potential conflicts of interest related to the publication of this article.

Received: 29.11.2019

Accepted: 26.07.2020

Olga S. Litvinova

Cand. (Geogr.) Sci., Associate Professor of the Departments of Geography, Regional Studies and Tourism, Novosibirsk State Pedagogical University, Novosibirsk, Russian Federation, ORCID: https://orcid.org/0000-0003-3225-5465, e-mail: olg.litwino2011@ yandex.ru 